SHORT REPORT

\title{
Sex ratio at birth among Chinese babies born in Italy is lower than in China
}

\author{
F Festini, G Taccetti, T Repetto, M L Cioni, M de Martino
}

J Epidemiol Community Health 2003;57:967-968

$\mathrm{n}$ industrial countries sex ratio at birth (SRB) (male/ female) varies between 1.07 and 1.03, with a decreasing trend in the past few decades. ${ }^{1}$ Population statistics of the past 20 years report that SRB in China is constantly and considerably increasing. According to official census data, the SRB of Chinese newborn babies was 1.168 in 2000 but in some provinces it exceeded 1.3. ${ }^{2}$ The increase of SRB has been a cause of concern in China as it is considered a possible cause of relevant social problems for the future, because of the increasing surplus of adult men without a female partner.

As no data are currently available about the SRB among Chinese living outside their homeland, we decided to calculate the SRB of an entire population of live births born during a decade to ethnic Chinese people settled abroad.

\section{PARTICIPANTS, METHODS, AND RESULTS}

Tuscany, a region in central Italy with 3.4 million inhabitants, has had a relevant influx of immigrants from China's People Republic since the early 1990s. According to Italian Statistics Bureau data, 17400 Chinese immigrants were living in Tuscany by the end of 2002 .

Using the data of the Tuscan neonatal screening programme for cystic fibrosis for the 1 July 1992 to 30 June 2002 period, on the basis of the information contained in the forms filled out at birth by the obstetricians, we separated the children born to both Chinese parents from other Tuscan babies. No children with just one Chinese parent were

\section{Key points}

- In an entire population of children born in Italy to Chinese immigrants in the past 10 years, sex ratio at birth was not as high as that reported in China, and it was similar to that of Italian newborn babies.

- The population of Chinese immigrants that was taken in to study did not abandon their cultural preference for sons, were not forbidden to know the sex of fetuses during pregnancies, and no limitation in the number of children was imposed to them by law.

- No other factors among those known to have an influence on sex ratio at birth seem to be responsible for the phenomenon we describe.

- The "one child family" rule seems to be an important cause of the high sex ratio at birth observed in China in the past 20 years.

reported. As the screening programme covers $99.9 \%$ of the region's newborn babies, ${ }^{3}$ we are confident that we analysed an entire population of Chinese infants born abroad. Then we calculated the SRB of the two groups both overall and by year, and their 95\% confidence intervals (95\%CI). Differences

Table 1 Comparison of the SRB of Chinese babies born in China with the SRB of Chinese and of non-Chinese babies born in Tuscany, 2000. Comparison between the SRBs of Chinese and non-Chinese babies born in Tuscany, Italy, 1992-2002

\begin{tabular}{|c|c|c|c|c|c|c|c|c|c|c|c|}
\hline \multirow[b]{3}{*}{ Period $t$} & \multicolumn{3}{|l|}{ A } & \multicolumn{3}{|l|}{ B } & \multirow[b]{2}{*}{ (A-B) } & \multicolumn{3}{|l|}{ C } & \multirow{3}{*}{$\begin{array}{l}(\mathrm{A}-\mathrm{C}) \\
\chi^{2} \mathrm{p} \text { value }\end{array}$} \\
\hline & \multicolumn{3}{|c|}{ Chinese babies born in Tuscany } & \multicolumn{3}{|c|}{$\begin{array}{l}\text { Non-Chinese babies born in } \\
\text { Tuscany }\end{array}$} & & \multicolumn{3}{|c|}{ Chinese babies born in China* } & \\
\hline & $\begin{array}{l}\text { Live } \\
\text { births }\end{array}$ & SRB & SRB 95\%Cl & Live births & SRB & SRB $95 \% \mathrm{Cl}$ & $\chi^{2} p$ value & Live births & SRB & SRB $95 \% \mathrm{Cl}$ & \\
\hline 2000 & 644 & 0.969 & 0.830 to 1.131 & 28247 & 1.058 & 1.033 to 1.082 & NS & 17721620 & 1.168 & 1.166 to 1.169 & 0.017 \\
\hline $1992-93$ & 159 & 1.120 & 0.821 to 1.527 & 24149 & 1.098 & 1.070 to 1.126 & NS & & & & \\
\hline 1993-94 & 180 & 0.978 & 0.731 to 1.308 & 241788 & 1.059 & 1.033 to 1.085 & & & & & \\
\hline $1994-95$ & 198 & 1.020 & 0.773 to 1.340 & 24334 & 1.066 & 1.039 to 1.093 & & & & & \\
\hline 1995-96 & 238 & 1.016 & 0.789 to 1.310 & 25076 & 1.068 & 1.042 to 1.095 & & & & & \\
\hline 1996-97 & 368 & 1.127 & 0.919 to 1.382 & 25826 & 1.049 & 1.024 to 1.075 & & & & & \\
\hline 1997-98 & 390 & 0.959 & 0.787 to 1.170 & 25695 & 1.071 & 1.056 to 1.109 & & & & & \\
\hline $1998-99$ & 490 & 0.983 & 0.824 to 1.173 & 26502 & 1.066 & 1.041 to 1.092 & & & & & \\
\hline $1999-00$ & 560 & 1.066 & 0.903 to 1.258 & 27699 & 1.075 & 1.050 to 1.101 & & & & & \\
\hline $2000-01$ & 693 & 0.957 & 0.825 to 1.111 & 28677 & 1.056 & 1.032 to 1.081 & & & & & \\
\hline $2001-02$ & 869 & 1.109 & 0.971 to 1.267 & 28611 & 1.047 & 1.023 to 1.072 & & & & & \\
\hline $\begin{array}{l}\text { 1st half } \\
1992-97\end{array}$ & 1143 & 1.059 & 0.943 tol.189 & 124173 & 1.067 & 1.055 to 1.078 & NS & & & & \\
\hline $\begin{array}{l}\text { 2nd half } \\
1997-02\end{array}$ & 3002 & 1.024 & 0.953 to 1.100 & 137184 & 1.063 & 1.052 to 1.074 & NS & & & & \\
\hline $\begin{array}{l}\text { Overall } \\
1992-02\end{array}$ & 4145 & 1.033 & 0.972 to 1.098 & 261357 & 1.065 & 1.057 to 1.073 & NS & & & & \\
\hline
\end{tabular}

* Sources: China Population Statistics Yearbook 2001, China Statistics Press, National Bureau of Statistics of the People's Republic of China, 2001 and US Census Bureau data, available at http://www.census.gov. †Periods are calculated from 1 July of one year to 30 June of another, except for the year 2000. 


\section{Policy implications}

- A substantial mitigation or the abolishment of the "one child family" rule in China may solve the problem of the high sex ratio at birth observed in China in the past 20 years.

of SRB between non-Chinese Tuscan newborn and Chinese born in Tuscany, as well as between Chinese born in Tuscany and Chinese babies born in China, were analysed with $\chi^{2}$ test $\mathrm{p}$ values.

The number of live births in the decade under investigation was 265 502. Among them, the number of infants born to ethnic Chinese immigrants was 4145. In Table 1 the SRB of Chinese immigrants' babies is compared with the SRB of other Tuscan infants and to the SRB of babies born in China in 2000. China's SRB for the 1992-2002 period is only partially known. In any case, all available annual data show SRB values over $1.13 .^{4}$

\section{COMMENTS}

The SRB of the entire population of Chinese infants born in Tuscany is significantly lower than that of Chinese babies born in their homeland and is not different from that of nonChinese Tuscan babies.

To explain the high SRB found in China, besides the well known strong cultural preference for sons ${ }^{245}$ a wide use of ultrasonography for antenatal sex detection and selective abortion of female fetuses has been described despite laws that strictly prohibit such practice. ${ }^{2} 5$

Moreover, a considerable under-registration of female births has been evidenced. ${ }^{2} 45$ The "one child family" policy introduced by China's authorities in 1979 has been considered among the possible causes of both of the described practices. ${ }^{25}$ Overlapping the traditional son preference, it has stimulated on the one hand antenatal sex selection-so that the only permitted child is a son-and on the other hand the under-reporting of female babies-so as not to deprive couples of another opportunity to have a son.
Our data are particularly interesting considering that in Tuscany antenatal sex detection is not prohibited and fetal ultrasonography, medical assistance during pregnancy, and abortion are provided free of charge to Chinese immigrants, whereas nothing suggests that they have abandoned their cultural preference for sons.

Many factors have been reported that influence SRB: medical factors (such as variations in sexual hormone levels, paternal and maternal age, etc), occupational exposures to substances and environmental pollutants. ${ }^{1}$ To our knowledge, no elements suggest a role of such factors in determining a lower SRB in Chinese born in our region.

Our data show that in social contexts in which a cultural preference for sons exists, the presence of rules limiting the number of children per family has a role in determining a higher SRB.

\section{Authors' affiliations}

F Festini, G Taccetti, T Repetto, M L Cioni, M de Martino, Cystic Fibrosis Centre, Meyer Paediatric Hospital, University of Florence, Italy

Funding: we thank Telethon Foundation Italy for its grant EC 1208/ 2000 .

Correspondence to: Dr F Festini, via L Giordano 13 Florence, 50132, Italy; filippo.festini@iol.it

Accepted for publication 11 May 2003

\section{REFERENCES}

1 Davis DL, Gottlieb MB, Stampnitzky JR. Reduced ratio of male to female births in several industrial countries. JAMA 1998;279:1018-23.

2 Plafker T. Sex selection in China sees 117 boys born for every 100 girls. BMJ 2002;324:1233.

3 Marianelli L, Taccetti G, Campana S, et al. Neonatal screening of the Tuscan population for cystic fibrosis using immunoreactive trypsinogen test molecular analysis on blood spot samples and measurements of lactase activity on meconium. [Abstract]. Telethon Foundation, Italy, grant no EC1 208. Proceedings of Telethon Scientific Convention, Rimini, Italy, Nov 2000:12-14.

4 Gu B, Roy K. Sex ratio at birth in China, with reference to other areas in East Asia: what we know. Asia-Pacific Population Journal 1995; 10:17-42.

5 Hesketh T, Zhu XW. Health in China: the one child family policy: the good, the bad, and the ugly. BMJ 1997;314:1685-7. 